AperTO - Archivio Istituzionale Open Access dell'Università di Torino

\title{
Management of inflammatory bowel disease during COVID-19 pandemic
}

\section{This is the author's manuscript}

Original Citation:

Availability:

This version is available http://hdl.handle.net/2318/1747966

since 2020-09-13T09:11:05Z

Published version:

DOI:10.23736/S1121-421X.20.02707-5

Terms of use:

Open Access

Anyone can freely access the full text of works made available as "Open Access". Works made available under a Creative Commons license can be used according to the terms and conditions of said license. Use of all other works requires consent of the right holder (author or publisher) if not exempted from copyright protection by the applicable law. 


\section{Management of inflammatory bowel disease during COVID-19 pandemic}

Journal: Minerva Gastroenterologica e Dietologica

Paper code: Minerva Gastroenterol Dietol-2707

Submission date: April 8, 2020

Article type: Editorial

Files:

1. Manuscript

Version: 1

Description: manoscritto

File format: application/msword 


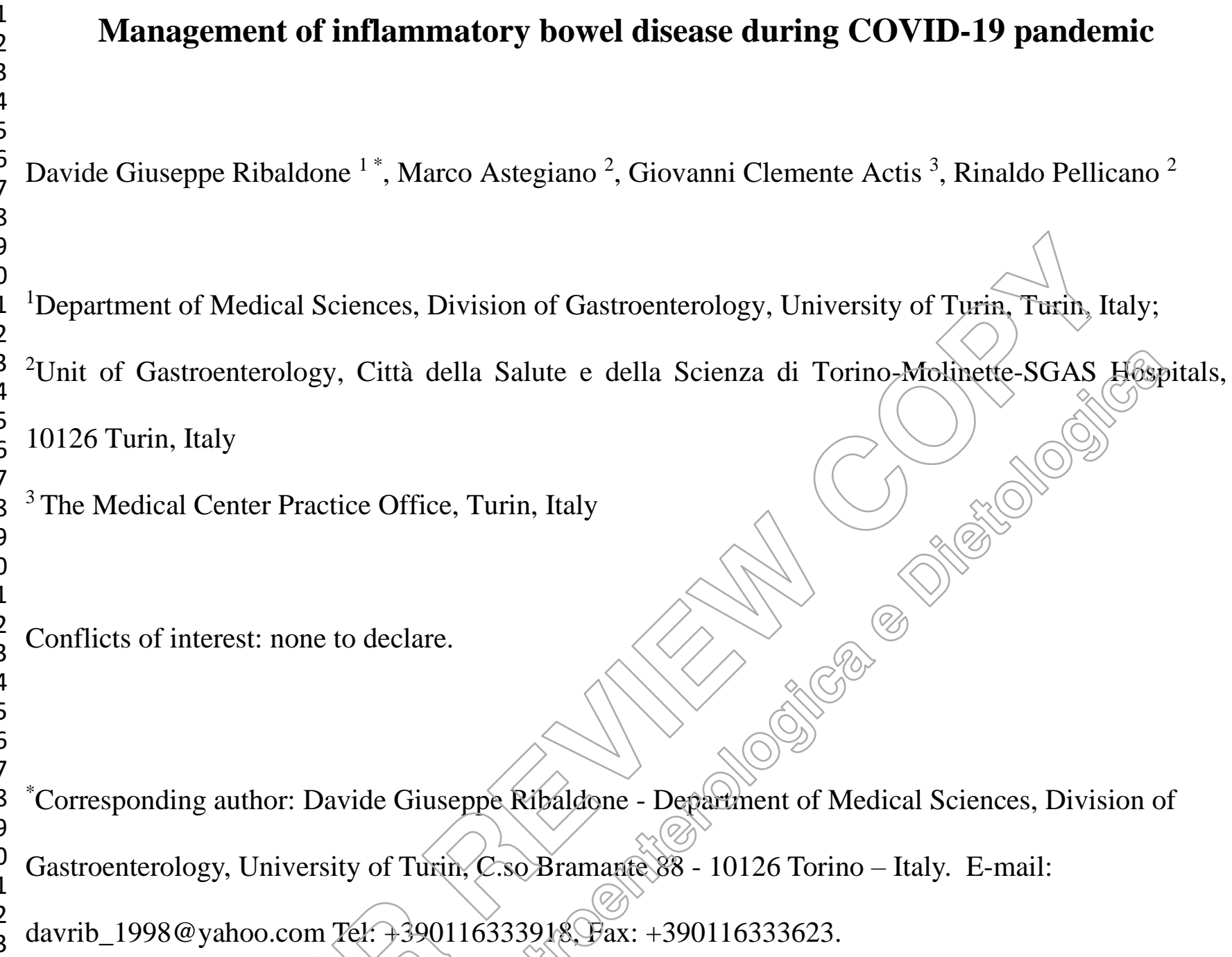

\section{Management of inflammatory bowel disease during COVID-19 pandemic}

Conflicts of interest: none to declare.

*Corresponding author: Davide Giuseppe Ribaldone - Department of Medical Sciences, Division of Gastroenterology, University of Turin, C.so Bramante 88 - 10126 Torino - Italy. E-mail: davrib_1998@yahoo.com Te1.+390116333918.Gax: +390116333623. ${ }^{2}$ Unit of Gastroenterology, Città della Salute e della Scienza di Torino-Molinetre-SGAS Hospitals, 10126 Turin, Italy

${ }^{3}$ The Medical Center Practice Office, Turin, Italy

Key words: $2019-n C_{b} V$ - Crohn S disease - SARS-CoV-2 - Telemedicine - Ulcerative colitis (1)

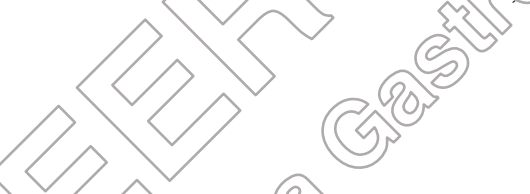


The new coronavirus pandemic, called COVID-19 (CoV-2), originated in China around November 2019 and has gradually spread all over the world, upsetting our lives. To date (April 4, 2020) more than 1 million people in the world have tested positive (and 10 times as many are likely to be infected) and around 60,000 have died (this figure also seems highly underestimated), Italy ranks first in this list, and the number of new infections is still increasing steadily. Mortality, which in Italy has exceeded $12 \%$ of the infected, seems to be conditioned by the presence of comorbidities such as high blood pressure, diabetes, chronic bronchitis. ${ }^{1}$ Thus, these conditions lead to frailty of the affected, patients. ${ }^{2,3}$ Inflammatory bowel diseases (IBDs) are not mentioned among these conditions.

IBDs are immune-mediated diseases in which a dysregulated reaction of the immune system towards the intestinal microbiome induces a chronic inflamnation that causes progressive damage. Despite an inflammatory core centred on the bowel, ${ }^{4}$ IBDs could be associated to several extra-intestinal manifestations. ${ }^{5}$ These diseases particularly affect young people, requiring a chronic management as well as the use of immunosuppressant and biological drigs ${ }^{6}$ raising obvious safety issues.

Furthermore, the digestive tract does not appeas to be immune from COVID-19 involvement. The antagonist angiotensin-eonverting enzymed (ACE2), which main function is to negatively regulate the renin-angiotensin system, is the COVily-19 gate to our cells. ${ }^{7}$ Lung, kidney, and gut cells all express ACE2 receptors. Not surprisingly, gastrointestinal symptoms are part (albeit with limited clinical importance) of the expression of the infection from severe acute respiratory syndrome (SARS)-CoV-2. ${ }^{8}$

To date, April 4, 2020, more than 275 cases of IBD patients infected by COVID-19 are reported worldwide. ${ }^{9}$ Obviously, we do not yet have data to know whether IBD patients are at an increased risk of COVID-19 infection due to the disease itself or because of the drugs they are treated with. ${ }^{10}$ In this perspective, a study published in 2009 could be informative. The authors used two mouse models permissive for a coronavirus experimental infection. Essentially, it was found that older but not 
1

2 4 5

younger animals responded with a "cytokine storm" including major pro-inflammatory cytokines and interferon (IFN), with the older succumbing to this mixture more than the younger. ${ }^{11}$ The key message is that disease behavior does mostly depend on host immunity, with full blown deadly reactions most probable at advanced age.

Coherently with this premise, the preference of IBD for younger age cohorts should reassure us on their outcomes in COVID infection; the role of medications in this context is mixed, however. The example of the possible beneficial role of tocilizumab (anti-interleukin-6 drug) in limiting the cytokine storm is an important example. ${ }^{12}$ In this regard, how should we advise our IBD patients?

Patients with IBD should not be routinely considered to have an altered irmonunocompetence per se, despite evidence of impaired innate mucosal immunity. If we can safely state that our patients can continue mesalazine therapy without concern, we know that the immunomodulators commonly used in IBD (corticosteroids, thiopurines, methotrexate, calcineurin inhibitors, anti-Tumor Necrosis Factor agents and other biologics) are associated with an increased risk of infections, especially if they are used in combination or in older patients. For corticosteroids, a total daily dose equivalent to $\geq 20 \mathrm{mg}$ of prednisolone for $\geq 2$ weeks is associated with an increased risk of infections. ${ }^{14}$

While the incidence of influenzadoes not appear greater in patients affected by IBD receiving immunomodulators, immusosuppression is generally considered to enhance the risk of severe/complicated infuenza infection and immunosuppressed patients with a laboratory diagnosis of influenza should receive timely treatment early in the course of illness. ${ }^{14}$ Withdrawal of immune suppression is advisable in the case of ascertained COVID-19 infection; yet, preemptive withdrawal is not wise, if considering a possible severe flare. ${ }^{15}$

Chronic IBD patients subjected to long-term treatment on one hand, and physical distancing measures on the other hand, will make a worsening challenge overcrowding our out-patient facilities. ${ }^{16}$ 
1 3

This could be the ideal test opportunity for telemedicine. The use of telemonitoring and teleconsulting seems to be safe and feasible with excellent patient acceptance. ${ }^{17}$ These can be implemented to enhance monitoring of disease activity and toxicity of therapy and promote empowerment and improvement of patient quality of life. However, this cannot be done by the individual clinician rather the Health Authority must fully be involved.

In conclusion, COVID superinfection will make a double endeavor on all physicians and IBD caregivers, reinforcing rules already applied for compromised hosts exposed to infeciion: prevent contact with potential sources, avoid starting therapeutic strategies with 2 immunomodulatory drugs, prompt suspension of these drugs in case of COVID-19 infection.

1. Zhou F, Yu T, Du R, Fan G, Liu Y, Liu Z, etal. Clinical course and risk factors for mortality of adult inpatients with COVID-19 in Wyihan, China: a retrospective cohort study. Lancet. 2020;

2. Zazzara MB, Yetrano DL, Carfi A, Onder G. Frailty and chronic disease. Panminerva Med. 2019 $\operatorname{Dec} 1 ; 61(4): 486-92$.

3. Petrini E, Cavigla AP, Pellicano R, Saracco GM, Morino M, Ribaldone DG. Risk of drug interactions and prescription appropriateness in elderly patients. Ir J Med Sci. 2019;

4. Newman KM, Vaughn BP. Efficacy of intestinal microbiota transplantation in ulcerative colitis: A review of current literature and knowledge. Vol. 65, Minerva Gastroenterologica e Dietologica. Edizioni Minerva Medica; 2019. p. 268-79.

5. Ribaldone DG, Pellicano R, Actis GC. The gut and the Inflammatory Bowel Diseases inside-out: 
the extra-intestinal manifestations. Minerva Gastroenterol Dietol. 2019 Apr 16;

6. Actis GC, Pellicano R, Fagoonee S, Ribaldone DG. History of Inflammatory Bowel Diseases. J Clin Med. 2019 Nov 14;8(11):1970.

7. Chen L, Li X, Chen M, Feng Y, Xiong C. The ACE2 expression in human heart indicates new potential mechanism of heart injury among patients infected with SARS-CoV-2. Cardiovasc Res. 2020 Mar 30;

8. Kotfis K, Skonieczna-Żydecka K. COVID-19: gastrointestinal symptoms and porential sources of 2019-nCoV transmission. Anaesthesiol Intensive Ther. 2020 Mar 23; कf

9. Current Data | Secure-IBD Database [Internet]. [cited 2020 Apr 4] vailable from: https://covidibd.org/current-data/

10. Monteleone G, Ardizzone S. Are patients with inflammarory bowel disease at increased risk for Covid-19 infection? J Crohns Colitis. $2020 \mathrm{Mar} 265$

11. Rockx B, Baas T, Zornetzer GA, Haagmans B, Sheahan T, Frieman M, et al. Early Upregulation of Acute Respiratory Distress Syndermie-Associated Cytokines Promotes Lethal Disease in an Aged-Mouse Model of Severe cute Respiratory Syndrome Coronavirus Infection. J Virol. 2009 Jul 15:83(14):7062-74.

12. Zhang C, Wu Z i I-W, Zhao H, Wang G-Q. The cytokine release syndrome (CRS) of severe COVID-19 and Interleukin-6 receptor (IL-6R) antagonist Tocilizumab may be the key to reduce the mortality. Int J Antimicrob Agents. 2020 Mar 28;105954.

13. Kmieć Z, Cyman M, Ślebioda TJ. Cells of the innate and adaptive immunity and their interactions in inflammatory bowel disease. Vol. 62, Advances in Medical Sciences. Medical University of Bialystok; 2017. p. 1-16. 
14. Rahier JF, Magro F, Abreu C, Armuzzi A, Ben-Horin S, Chowers Y, et al. Second European evidence-based consensus on the prevention, diagnosis and management of opportunistic infections in inflammatory bowel disease. J Crohn’s Colitis. 2014 Jun 1;8(6):443-68.

15. Fiorino G, Allocca M, Furfaro F, Gilardi D, Zilli A, Radice S, et al. Inflammatory bowel disease care in the COVID-19 pandemic era: the Humanitas, Milan experience. J Crohns Colitis. 2020 Mar 24;

16. Ribaldone DG, Adriani A, Caviglia GP, Nicolò A De, Agnesod D, Simiele M, et a1. Correlation between thiopurine S-methyltransferase genotype and adverse events in inflammatory bowel disease patients. Med. 2019;55(8).

17. Peris MA, Del Hoyo J, Bebia P, Faubel R, Barrios A, Bastida G, inflammatory bowel disease: Opportunities and approaches.linflamm Bowel Dis. 2015 Feb;21(2):392-9. 